\title{
Origin and evolution of the vertebrate vomeronasal system viewed through system-specific genes
}

\author{
Wendy E. Grus and Jianzhi Zhang*
}

\begin{abstract}
Summary
Tetrapods have two distinct nasal chemosensory systems, the main olfactory system and the vomeronasal system (VNS). Defined by certain morphological components, the main olfactory system is present in all groups of vertebrates, while the VNS is found only in tetrapods. Previous attempts to identify a VNS precursor in teleost fish were limited by functional and morphological characters that could not clearly distinguish between homologous and analogous systems. In the past decade, several genes that specifically function in the VNS have been discovered. Here we first describe recent evolutionary studies of mammalian VNS-specific genes. We then review evidence showing the presence and tissuespecific expression of the VNS-specific genes in teleosts, as well as co-expression patterns of these genes in specific regions of the teleost olfactory epithelium. We propose that a VNS precursor exists in teleosts and that its evolutionary origin predated the separation between teleosts and tetrapods. BioEssays 28:709-718, 2006. (C) 2006 Wiley Periodicals, Inc.
\end{abstract}

Department of Ecology and Evolutionary Biology, University of Michigan, Ann Arbor, Ml.

Funding agency: This work is supported by research grants from University of Michigan and National Institutes of Health to J.Z. W.E.G. is supported by the National Institutes of Health training grant T32HG000040.

${ }^{*}$ Correspondence to: Jianzhi Zhang, Department of Ecology and Evolutionary Biology, University of Michigan, 1075 Natural Science Building, 830 North University Avenue, Ann Arbor, MI 48109.

E-mail: jianzhi@umich.edu

DOI 10.1002/bies.20432

Published online in Wiley InterScience (www.interscience.wiley.com).

Abbreviations: AOB, accessory olfactory bulb; CaSR, $\mathrm{Ca}^{2+}$-sensing receptor; DAG, diacylglycerol; GPCR, G-protein coupled receptor; $\mathrm{IP}_{3}$, inositol 1,4,5-triphosphate; MOS, main olfactory system; OR, odorant receptor; ORF, open reading frame; PLC, phospholipase C; T1R, sweet/umami taste receptor; T2R, bitter taste receptor; Trpc2, transient receptor potential cation channel, subfamily $\mathrm{C}$, member 2; V1R, vomeronasal receptor superfamily 1 ; V2R, vomeronasal receptor superfamily 2; VNO, vomeronasal organ; VNS, vomeronasal system.

\section{Introduction}

Nearly two centuries ago, Ludwig Jacobson described a new organ in the nasal cavity of mammals. ${ }^{(1)}$ This organ is now known as Jacobson's organ or the vomeronasal organ (VNO), because of its proximity to the vomer bone in the nasal cavity. The location of this organ suggests that it is involved in detecting smells (Fig. 1). Indeed, the vomeronasal system (VNS) is used for nasal chemoreception, but it is secondary to the main olfactory system (MOS), in both its size and evolutionary origin. The MOS is found in almost all vertebrates, ${ }^{(2)}$ while the VNS is tetrapod-specific, found only in amphibians, reptiles, and mammals. In most taxa with both types of nasal chemosensory systems, the main olfactory epithelium is much larger in area than the VNO sensory epithelium. However, exceptions to this rule are abundant in some groups of snakes and lizards.

Why do some vertebrates need two nasal chemosensory systems? This question is difficult to answer because the functions of the two systems are not distinctively different. It was initially thought that the MOS is used to detect environmental chemical cues while the VNS is a terrestrial adaptation for detecting volatile pheromones, which are chemical cues released and sensed by individuals of the same species. In tetrapods, experiments confirmed that the VNS plays an important role in pheromone-mediated behaviors, such as reproduction and parenting. ${ }^{(3-8)}$ However, studies also found other roles for the VNS. For example, in both amphibians and reptiles, the VNS plays a role in foraging. ${ }^{(4,9-11)}$ Additionally, the MOS can mediate pheromone-induced behavior, ${ }^{(12,13)}$ and known pheromones excite both the main olfactory bulb, the region of the brain excited by the MOS, and the accessory olfactory bulb $(A O B)$, the region of the brain excited by the VNS. ${ }^{(14)}$ Thus, despite their distinct morphologies, the MOS and VNS are functionally related. To determine whether this interrelatedness is due to functional convergence or shared evolutionary ancestry, it is important to understand the evolutionary origins of the two systems.

To address the above evolutionary question, one has to be able to recognize the VNS. Originally, the VNS was characterized solely by two morphological features, the VNO and the 


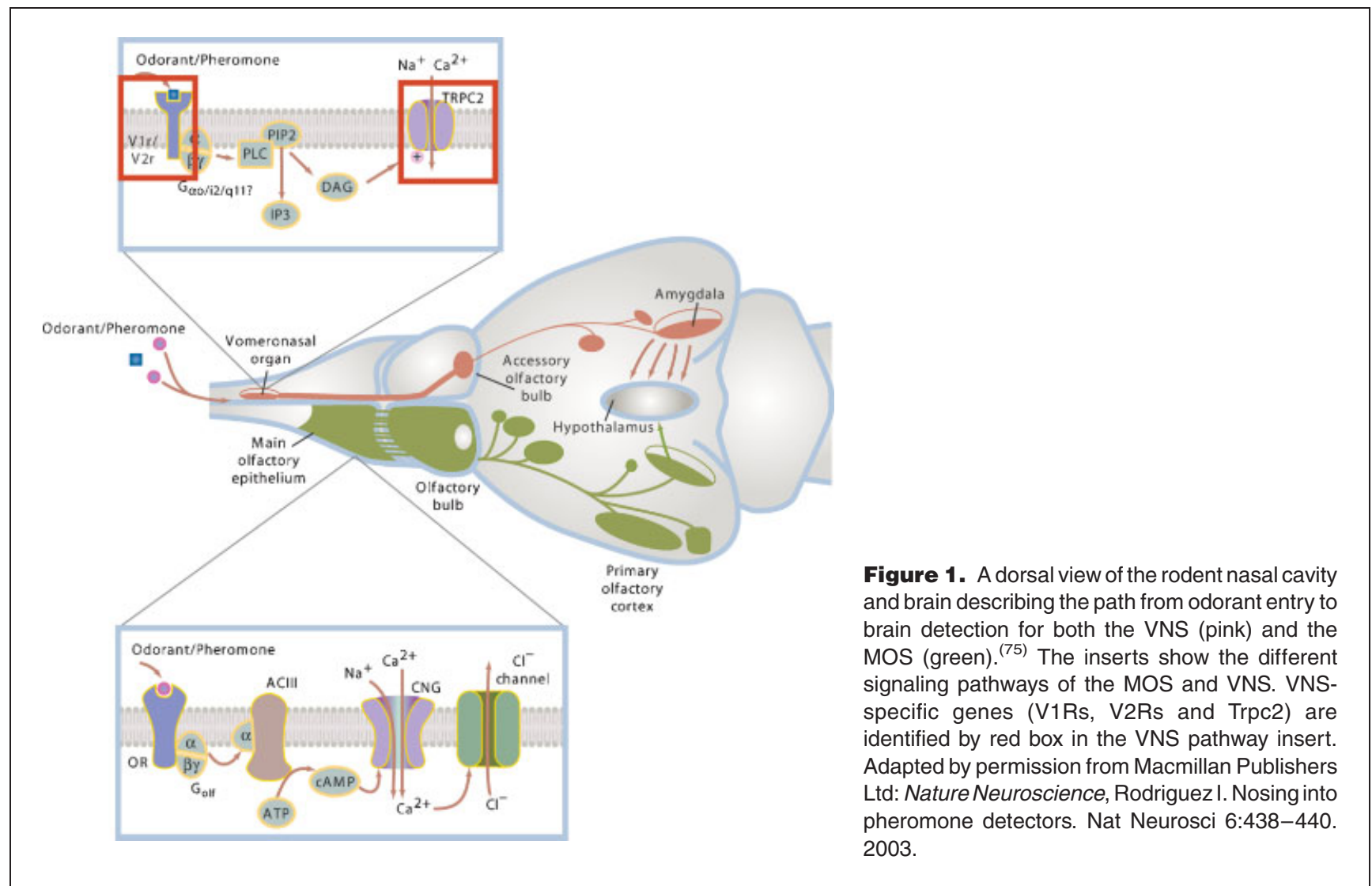

AOB (Fig. 1). These key morphological components appear first in amphibians and are absent in teleosts and lungfishes. ${ }^{(15)}$ Because the morphological components of the VNS apparently arose in amphibians, Bertmar ${ }^{(16)}$ hypothesized that the VNS originated in early tetrapods as an adaptation to terrestrial life. Eisthen ${ }^{(15)}$ rejected this hypothesis because the VNS develops during the aquatic larval stage of amphibians and is apparently important in both aquatic and terrestrial stages. Recent evolutionary studies support the view that the VNS did not arise as an adaptation to terrestrial life, but fail to offer an alternative, stating only that the VNS originated in early aquatic amphibians. ${ }^{(17,18)}$

If the VNS did not arise as a terrestrial adaptation, perhaps a homologous or precursor system exists in fish. Since the VNS is hypothesized to detect pheromones, Dulka ${ }^{(19)}$ compared the goldfish sex pheromone system to the VNS. While acknowledging functional and anatomical similarities in terms of distinct brain regions innervated by different olfactory neurons, a comparison based solely on morphological and functional similarities between fish and tetrapod receptor cells did not provide sufficient evidence to conclude whether these systems are homologous or analogous. ${ }^{(19)}$ However, Eisthen ${ }^{(15)}$ suggested that the teleost microvillar olfactory cells correspond to the tetrapod microvillar vomeronasal cells while the teleost ciliated olfactory cells correspond to the tetrapod ciliated olfactory cells. Hence, the teleost microvillar olfactory cells could represent an unrecognized form of VNS in teleost fish. ${ }^{(15)}$ How could this be verified ${ }^{(20)}$ In the past decade, VNS-specific geneshave been identified and, presuming they maintain their system-specific functions in non-tetrapod vertebrates, this supports the presence of a VNS precursor.

The signal transduction pathway for VNS chemoreception has become increasingly clear in recent years (Fig. 1 and reviewed in Ref. 21). The signal is initiated by a ligand binding to one of two types of VNS-specific G-protein-coupled receptors (GPCRs). This binding alters the conformation of the receptor, leading to the release of the $G$ protein, which activates phospholipase C (PLC). The activated PLC increases levels of two secondary messengers, diacylglycerol (DAG) and inositol 1,4,5-triphosphate $\left(\mathrm{IP}_{3}\right) .{ }^{(22)}$ Both DAG and $\mathrm{IP}_{3}$ increase the intracellular calcium level; DAG by activating the Trpc2 channel allowing an inward calcium flux and $\mathrm{IP}_{3}$ by allowing the release of intracellular calcium stores. While some of these signal transduction molecules are common to other signal transduction pathways, three types of VNS genes (V1Rs, V2Rs, and Trpc2) are known to function in the VNSspecific chemoreception. The functions of these genes have been recently reviewed. ${ }^{(23,24)}$ Here we focus on the evolution

\section{BioEssays 28.7}


of these genes with the hope of understanding the origin and evolution of the VNS. Compared with the current view of VNS evolution based on morphological components, the evolution of these VNS-specific genes would give a different perspective. Below we first describe the evolution of VNS-specific genes in mammals. We then show that homologous genes are found in non-tetrapod vertebrates and describe the evolution of these genes in teleost fish. Finally, we discuss expression studies that indicate an earlier origin of the VNS signal transduction pathway.

V1Rs: a vomeronasal receptor gene superfamily Vomeronasal receptors belong to two large unrelated GPCR superfamilies, V1Rs and V2Rs. ${ }^{(25-28)}$ V1Rs were first identified from rat VNS neurons and, like odorant receptors (ORs), were predicted to represent a large ( 100 genes) superfamily. ${ }^{(25)}$ Also like ORs, V1Rs have intron-less coding regions. Surprisingly, V1Rs are not closely related to ORs but instead are most closely related to T2R bitter taste receptors. ${ }^{(29)} \mathrm{V} 1 \mathrm{Rs}$ are expressed in the apical VNS sensory neurons in rodents and coupled to $\mathrm{G}_{\alpha \mathrm{i} 2} \mathrm{G}$ proteins. ${ }^{(21)}$ Besides VNS expression, nine V1R genes were found to be expressed in the testis and hypothesized to play a role in sperm maturation or migration. ${ }^{(30)}$ However, when these and other V1Rs were knocked out, the mutant mice were fertile. ${ }^{(6)}$ Therefore, V1Rs are known to function only in the VNS. The knockout study also indicated that the V1Rs play a role in pheromone communication as the mutant mice showed reduced maternal aggression and decreased male sexual behavior. ${ }^{(6)}$ Additionally, VNS neurons with a mutated form of the gene $V 1 R b 2$ did not respond to 2-heptanone, a known mouse pheromone. ${ }^{(31)}$ These two studies demonstrate that at least some V1Rs are pheromone receptors, but they do not exclude the possibility that other V1Rs can detect non-pheromonal chemicals. In any case, because the functions of V1R receptors are VNS specific, the evolution of mammalian V1Rs indicate the evolution of the mammalian VNS.

Because of their simple structure, V1R genes have been identified in many mammals, and the full repertoires have been described for representatives of five placental and marsupial mammalian orders based on analyses of complete genomes sequences (Fig. 2). ${ }^{(29,32-37)}$ Mouse and rat V1R genes can be divided into 15 families based on amino acid sequence identity and phylogenetic relationships. ${ }^{(29,36)}$ Most of these families were present at the time of the placental mammal radiation. ${ }^{(33,36)}$ A comparison between mouse and rat V1Rs revealed mechanisms by which species-specific $V 1 R$ repertoires were generated. For example, a V1R family that existed in the mouse-rat common ancestor may be lost entirely in the rat lineage and thus appear to be mouse-specific. ${ }^{(33,35,37)}$ Because mice and rats have large repertoires of functional $\mathrm{V} 1 \mathrm{Rs}^{(37)}$ and humans (with a nonfunctional VNS) have a large number of $\mathrm{V} 1 \mathrm{R}$ pseudogenes, ${ }^{\left({ }^{32}\right)}$ it was expected that all

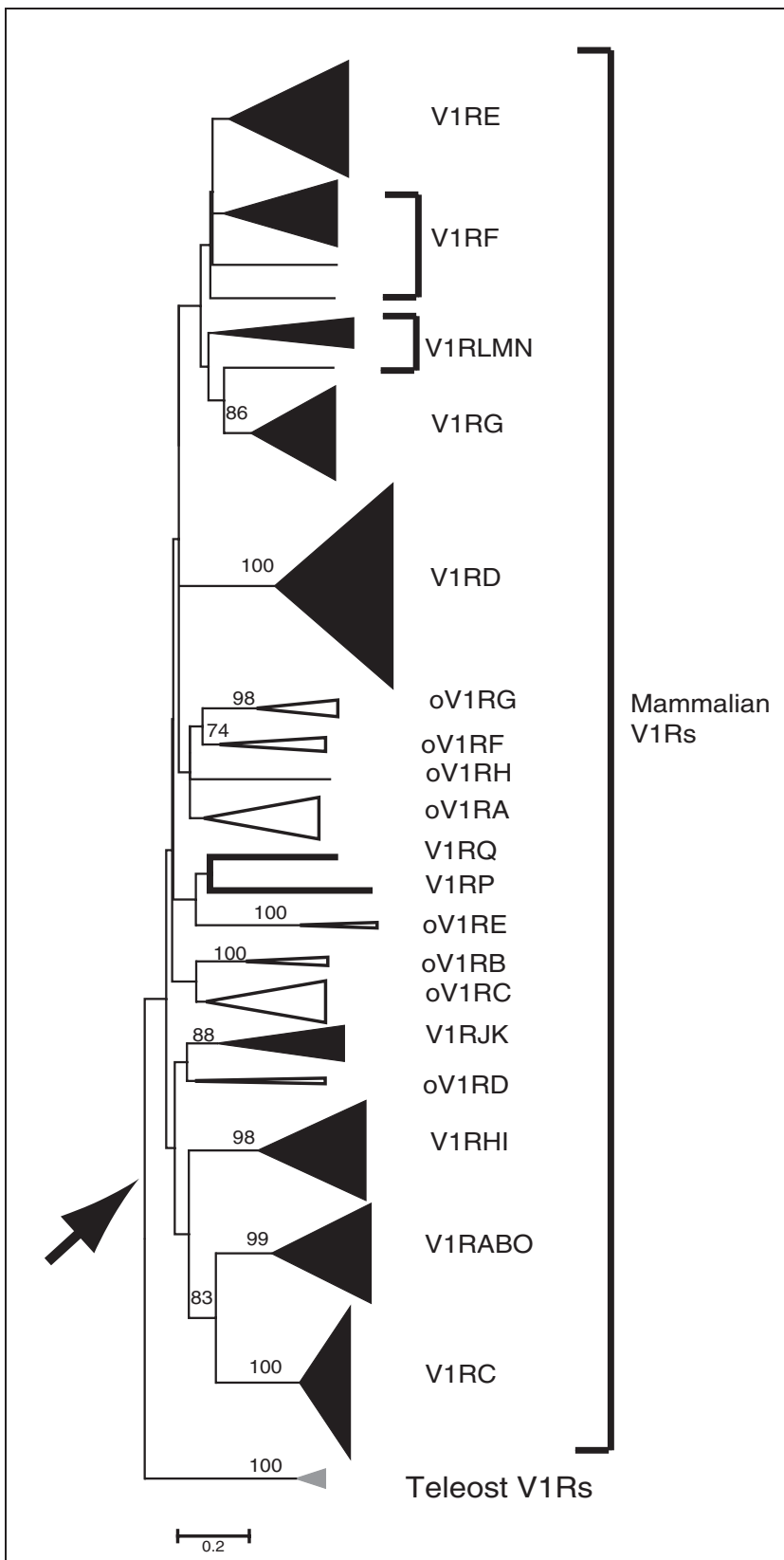

Figure 2. Phylogenetic reconstruction of putatively functional V1Rs containing single genes from 5 teleost species, ${ }^{(62)} 187$ mouse genes, ${ }^{(49)} 106$ rat genes, ${ }^{(49)} 32$ cow genes, ${ }^{(36)} 49$ opossum genes, ${ }^{(36)}$ and 8 dog genes. ${ }^{(36)}$ Placental mammalian $\mathrm{V} 1 \mathrm{R}$ families are condensed as black triangles and denoted with V1R family names from ref. 36 . Opossum V1R families are condensed as open triangles and denoted with oV1R family names from ref. 36 . Teleost V1R genes are condensed as a gray triangle. The arrow indicates where the tree is rooted with T2Rs as an outgroup. Bootstrap percentages greater than 70 are given. The tree was reconstructed using the neighborjoining method ${ }^{(76)}$ with Poisson-corrected protein distances. The scale bar shows 0.2 amino acid substitutions per site. Phylogenetic reconstruction made in MEGA3. ${ }^{(77)}$ 
mammals would have a large V1R repertoire. However, subsequently released mammalian genome sequences showed that a large V1R repertoire is not a general trend in mammals. ${ }^{(35,36)}$ For example, dogs and cows have only 8 and 32 functional V1R genes, respectively. ${ }^{(35,36)}$ In fact, the among-species variation in the number of functional V1R genes is the largest among all known gene families of mammals. ${ }^{(36)}$

What accounts for this dramatic variation in the size of themammalian $\mathrm{V} 1 \mathrm{R}$ repertoire? First, lineage-specific duplications may explain the size difference. Initial studies of rodent $\mathrm{V} 1 \mathrm{R}$ evolution suggested that the large gene family arose from duplications around the time of the mouse-rat divergence. $^{(38,39)}$ However, some V1R families have duplications either much older or much younger than the mouse-rat divergence. ${ }^{(33)}$ Lane et al. ${ }^{(38,39)}$ suggested that rodent V1R duplications were mediated via $L 1$ repetitive element activity. While these elements are found in high density near the rodent V1R clusters, they are not found in high density around the dog V1R genes, ${ }^{(36)}$ suggesting that the repertoire size difference may be due in part to the lack of a mechanism to generate new V1R genes. Second, the V1R repertoire size appears correlated with the morphological complexity of the VNO. Takami ${ }^{(40)}$ described three different complexity levels of the mammalian VNO. Rodents and opossums have the most complex type of mammalian VNO with a thick layer of sensory epithelium. Interestingly, these organisms have the largest $\mathrm{V} 1 \mathrm{R}$ repertoires among mammals. ${ }^{(36)}$ Dogs and cows have a less complex VNO with a much thinner layer of sensory epithelium, and these mammals have smaller V1R repertoires. ${ }^{(36)}$ In humans, the VNO is either absent or nonfunctional and humans and chimpanzees have only a few V1Rs with intact open reading frames (ORFs). ${ }^{(41)}$ Finally, the difference in repertoire size could be due to functional differences between the VNS of the different mammals (although this difference might also be related to VNO complexity). The different V1R families might also vary in function. However, without knowing the exact function of the $\mathrm{VNS}^{(42)}$ or the V1Rs, the effect of function on repertoire size remains difficult to evaluate.

These explanations for the size variation of $\mathrm{V} 1 \mathrm{R}$ repertoires could be further tested with complete V1R repertoires from additional species. However, the rapid evolution of this gene superfamily makes it difficult to design primers that will amplify homologous genes across species. ${ }^{(43)}$ Such cross-species amplifications probably work only in closely related species and give only a subset of the V1R repertoire. ${ }^{(43)}$ Comparisons of $\mathrm{V} 1 \mathrm{R}$ subsets have been done on many primate species in an attempt to compare the $\mathrm{V} 1 \mathrm{R}$ repertoires of primates with a functional VNS and those with a nonfunctional VNS. ${ }^{(43,44)}$ However, these studies mainly identified pseudogenes regardless of whether or not the primate species has a functional VNS.
Because pheromones are intraspecific signals, it would be interesting to examine sequence variation of $\mathrm{V} 1 \mathrm{Rs}$ within a species and that between two closely related species. Using two different mouse genome sequences, Zhang et al. ${ }^{(34)}$ identified variations in the V1R repertoires between different strains of mice. Their results suggest that the rate of nonsynonymous changes exceeds that of synonymous changes, a signal of positive Darwinian selection. However, the observed between-strain differences may have been a result of mouse breeding (and thus artificial selection). The natural levels of and evolutionary forces on intraspecific V1R variations remain unclear. The intraspecific variations of the five human V1R genes with ORFs have also been studied ${ }^{(41)}$ and the results appear to indicate that these five genes are evolving neutrally, consistent with the hypothesis that they are relics of an on-going pseudogenization process.

\section{V2Rs: another vomeronasal receptor superfamily}

In contrast to V1Rs, V2Rs have a more-complex gene structure with multiple introns breaking the coding region. As a result, mammalian $\mathrm{V} 2 \mathrm{R}$ evolution has not been studied in as much detail. V2Rs are closely related to the $\mathrm{Ca}^{2+}$-sensing receptors (CaSRs) and metabotropic glutamate receptors and are homologous to T1R sweet/umami taster receptors. But, interestingly, V2Rs do not show significant sequence similarity to either V1Rs or ORs. Despite their complexity, V2R genes were the first type of VNS-specific genes identified in nonmammalian taxa. ${ }^{(45,46)}$ Their expression in rodent basal sensory neurons also makes them spatially segregated from the V1Rs, and there they couple to $G_{\alpha 0}$ G proteins. ${ }^{(21)}$ V2R expression has also been detected during mouse embryonic development in the VNO as well as other neural tissues. ${ }^{(47)}$ The V2R function during development in these neural tissues is not well understood, but other molecules in the V2R signaling cascade were also expressed in these tissues, indicating that V2Rs might contribute to neural functions during development. ${ }^{(47)}$ Does this extra-VNS function discount V2Rs as suitable genetic markers for a VNS precursor? While developmental V2R expression should be evaluated in other vertebrates, given the limited distribution of V2Rs among mammals (putatively functional V2Rs have only been identified in mice, rats and opossums; P. Shi and J.Z., unpublished), the role of V2Rs during development is likely newly derived rather than ancestral. In fact, only mammals with the mostcomplex VNO type ${ }^{(40)}$ seem to have segregated expressions of $\mathrm{G}$ proteins in the VNO that correspond to V1Rs and V2Rs, ${ }^{(48)}$ whereas those with the less complex VNOs appear to lack functional V2Rs. ${ }^{(36)}$ If the developmental function of V2Rs is both ancestral and essential, it would have been conserved across the mammalian taxa.

Despite having a more limited mammalian distribution, functional V2R repertoires can also provide a new view on

\section{BioEssays 28.7}


VNS evolution. The identified functional V2R repertoires are smaller than the V1R repertoires in mice and rats. ${ }^{(37,49)}$ Based on protein sequence similarity and phylogenetic relationships, V2Rs are divided into three families $(A-C) .{ }^{(49)}$ Determined from a phylogenetic reconstruction of V2Rs, CaSRs and T1Rs, the three V2R families are not monophyletic (Fig. 3). ${ }^{(49)}$ Thus, V2Rs may have had two independent origins (A/B and C). ${ }^{(49)}$ Similar to V1Rs, the V2Rs exhibit rapid evolution characterized by gene-sorting, differential gains and losses of gene family members across species. ${ }^{(49,50)}$ Additionally, the long $\mathrm{N}$ terminal region is targeted by positive selection for amino acid substitutions. ${ }^{(49)}$ While the rapidly evolving V1Rs and V2Rs explain the evolution of the VNS within mammals, a more-conserved gene is necessary for studying the evolution of the VNS between vertebrate classes. Trpc2 is one such gene.

\section{Trpc2 channel protein shows VNS-specific function}

Besides the vomeronasal receptor superfamilies, the signal transduction channel protein Trpc2 (also known as Trp2) is specific to the VNS. Trpc2 is a member of the Trp gene family, which has been highly conserved among distantly related invertebrates and vertebrates. From the rat VNO, Liman et al. ${ }^{(51)}$ identified Trpc2 expression. This gene was the homolog of a mouse Trp gene that is also expressed in the testis. ${ }^{(52)}$ However, testis expression was not observed in rat. ${ }^{(51)}$ Further studies of Trpc2 in mouse testis indicate that DAG, which activates Trpc2 in the VNS, does not activate Trpc2 for its acrosomal function in testis. ${ }^{(53)}$ Instead, junctate, an $\mathrm{IP}_{3^{-}}$ associated protein, activates Trpc2 in the testis. ${ }^{(53)}$ Without knowing the sequence of the junctate-binding site on Trpc2, we cannot know if this binding site is unique to mouse Trpc2. However, because Trpc2 is expressed in the testis of some other mammals, ${ }^{(54)}$ Trpc2 may have an additional function in the testis that is different from its role in the VNS. As Trpc2 is alternatively spliced, splice variants might correspond to these two functional variants. Intact Trpc2 genes have been found in taxa with a VNS, while Trpc2 pseudogenes are identified in those taxa that lack a functional $\mathrm{VNO},{ }^{(41,55)}$ suggesting that Trpc2's role in testis, if it exists, is not universally important. Thus, the main role of Trpc2 is in the VNS. Mutant mice for Trpc2 showed difficulty distinguishing genders, decreased aggressive behavior and decreased territoriality, ${ }^{(7,8)}$ supporting Trpc2's involvement in pheromone detection.

Two evolutionary studies of the VNS focused on the pseudogenization of Trpc2 in primates. ${ }^{(41,55)}$ These studies find that, while Trpc2 in New World monkeys remains putatively functional, Old World monkeys and hominoids (humans and apes) have a pseudogenized copy of Trpc2. ${ }^{(41)}$ A shared stop codon among Old World monkeys and hominoids indicates that Trpc2 was pseudogenized in the

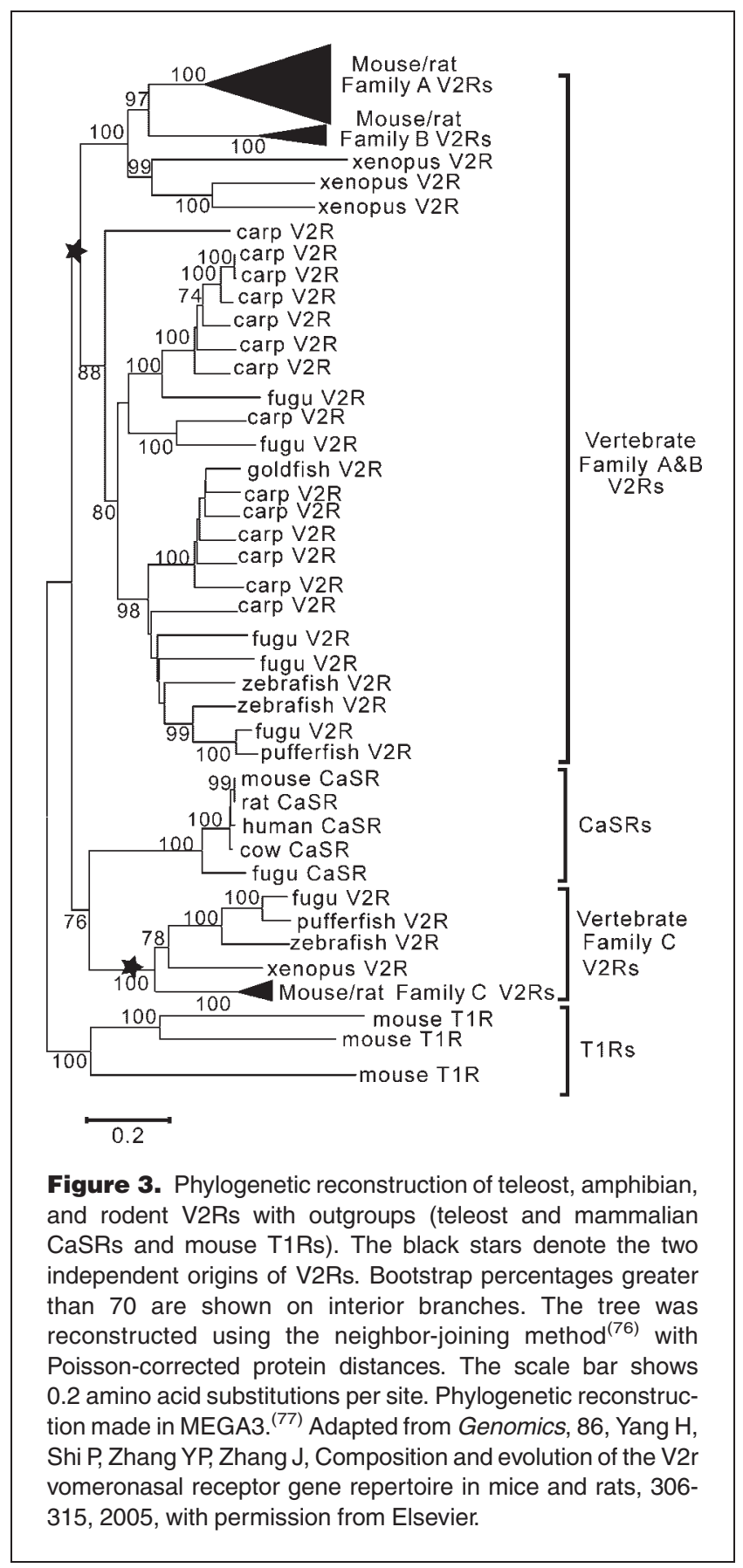

common ancestor of these two groups. ${ }^{(41)}$ The inactivation of Trpc2 about 23 million years ago could possibly be the result of the shift to the full trichromatic visual communication from pheromonal communication. ${ }^{(41)}$ Similarly, Trpc2 is not found in the chicken genome, consistent with the lack of the VNS in birds. The parallel loss of Trpc2 and a functional VNS indicates that the evolution of this gene reflects the evolution of the VNS and demonstrates the validity of the approach of using Trpc2 as a marker for studying VNS evolution. 


\section{Not all VNS genes are suitable markers of VNS evolution}

In addition to V1Rs, V2Rs and Trpc2, there are other genes that function in the VNS. Why do we focus on these three types of genes? First, to establish the presence of a homologous physiological system (or a system precursor) by the presence of homologous genes, the gene must be system-specific. ${ }^{(56,57)}$ Therefore, components of the VNS signal transduction pathway that are also found in other signal transduction pathways, such as PLC, DAG, IP, $\mathrm{G}_{\alpha \mathrm{i} 2}$ or $\mathrm{G}_{\alpha \mathrm{0}}$, are not suitable markers for studying the origin and evolution of the VNS. Additionally, genes that function in the VNS of a small number of evolutionary lineages are not useful because those genes are not part of the ancestral molecular definition of the system. For example, rodent V2Rs selectively co-express with M10 and M1 families of MHC class $1 \mathrm{~b}$ molecules. ${ }^{(58,59)} \mathrm{M} 10$ molecules function as escort molecules in the transport of V2Rs to the cell membranes of VNS neurons. ${ }^{(58,59)}$ However, this association appears to be rodent-specific, and thus $\mathrm{MHC}$ class $1 \mathrm{~b}$ molecules cannot be used to establish a homologous system in non-tetrapod vertebrates. ${ }^{(59)}$ Only those genes with ancestral and system-specific function can be used to trace VNS evolution. However, the presence of these genes would not suggest that the VNO arose earlier in vertebrate evolution. Rather, it would suggest that the molecular genetic architecture of the VNS arose earlier in vertebrate evolution. While some genes change function and expression over time, ${ }^{(60)}$ identifying these genes functioning together in specific cells and pathways would strongly support the presence of an earlier origin for the VNS.

\section{VNS-specific genes suggest an earlier origin of the VNS-signal transduction pathway}

Initial attempts to isolate V1R sequences from non-mammalian tetrapods were unsuccessful. ${ }^{(61)}$ However, a single V1R gene was recently identified from the olfactory organ of several teleost fishes. ${ }^{(62)}$ Interestingly, these teleost V1Rs do not exhibit the same gene-sorting evolutionary pattern found in mammalian $\mathrm{V} 1 \mathrm{Rs}^{(33,35-37,62)}$ When a phylogenetic reconstruction of the vertebrate V1Rs is rooted with T2Rs, the V1Rs form a monophyletic clade, indicating a single origin for this gene superfamily. The mammalian V1Rs and the previously identified teleost $\mathrm{V} 1 \mathrm{Rs}$ are reciprocally monophyletic (Fig. 2). If this topology is correct, a single ancestral V1R was present in the common ancestor of teleosts and tetrapods. This topology could be further confirmed by including intermediate taxa (i.e. amphibians or reptiles) in the V1R phylogeny when $\mathrm{V} 1 \mathrm{R}$ sequences from these taxa become available.

In contrast to V1Rs, multiple V2Rs have been identified from several teleost taxa. Studying the olfactory epithelium of goldfish, Cao et al. ${ }^{(45)}$ found segregated expression of two types of chemosensory receptors similar to ORs and V2Rs. Additionally, V2Rs were identified in frogs and other teleost fishes. ${ }^{(46,61,63-66)}$ The discovery of vomeronasal receptors in teleost fish, coupled with the previous receptor cell type studies, ${ }^{(15,19)}$ suggests that a VNS precursor exists in teleost fish. Teleost genes in this family have been called "V2R-like" genes. ${ }^{(63)}$ However, as shown in Fig. 3, the teleost receptors cluster with the tetrapod V2Rs and, thus, on the molecular level are vomeronasal receptors. In addition to the rat and mouse, the V2R repertoire of zebrafish has been described. ${ }^{(66)}$ Teleost V2Rs were identified from each of the two independently evolved V2R types (Fig. 3), indicating that both of these two types existed in the common ancestor of teleosts and tetrapods. The evolution of the teleost V2Rs is similar to that of mammalian V2Rs, with species-specific expansions (Fig. 3). While the $\mathrm{V} 1 \mathrm{R}$ repertoire probably expanded in tetrapods and the $\mathrm{V} 2 \mathrm{R}$ repertoire expanded in both tetrapods and teleosts, both V1R and V2R genes were

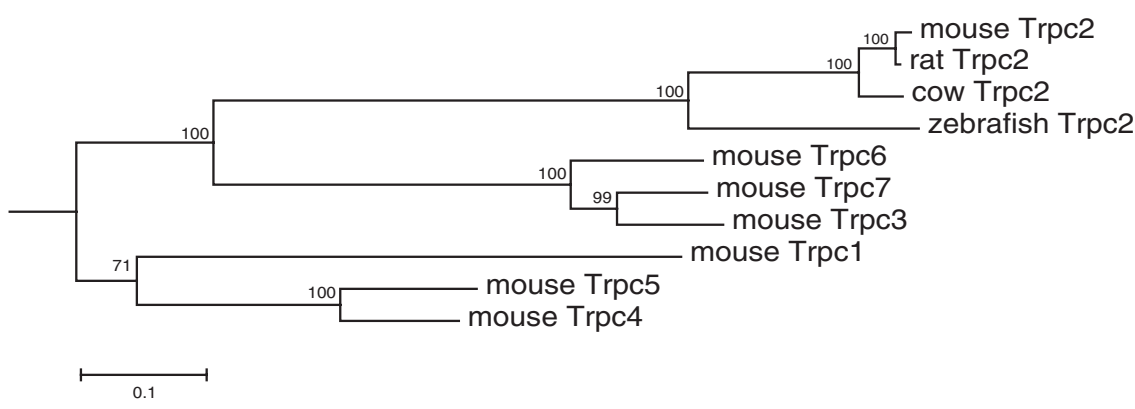

Figure 4. Phylogenetic reconstruction of mouse Trpc proteins and rat, cow, and zebrafish Trpc2 proteins. The tree is rooted with Drosophila melanogaster Trp and Trpl proteins. Bootstrap percentages are given. The tree was reconstructed using the neighbor-joining method $^{(76)}$ with Poisson-corrected protein distances. The scale bar shows 0.1 amino acid substitutions per site. Phylogenetic reconstruction made in MEGA3. ${ }^{\text {(77) }}$ (Genbank accession nos. for mouse Trpc1, Trpc3-7 are NP_035773, NP_062383, NP_058680, NP_033454, NP_038866, and NP_036165. Genbank accession nos. for mouse, rat, cow, and zebrafish Trpc2 are NP_035774, NP_072160, CAA06964, and NP_001025337. Genbank accession nos. for D. melaogaster Trp and Trpl are NP_476768 and NP_476895).

\section{BioEssays 28.7}


apparently present in the common ancestor of teleosts and tetrapods.

Trpc2 was also present in the common ancestor of teleosts and tetrapods. Previously, Trpc2 was detected in the musk turtle (Sternotherus odoratus) in a study of the signal transduction of the VNS, but it was not sequenced or characterized. ${ }^{(67)}$ Additionally, a secondary messenger in the signal transduction cascade for Trp proteins, $\mathrm{IP}_{3}$, functions in VNO neurons in frog, snake, and turtle, suggesting that Trpc2 is also a component of the amphibian and reptilian VNS. ${ }^{(68-70)}$ Trpc2 expression has also been observed in zebrafish olfactory epithelium. ${ }^{(65)}$ Phylogenetic analysis shows that the zebrafish Trpc2 gene clusters with the mammalian Trpc2 clade with high bootstrap support (Fig. 4) and shares about 65\% protein sequence identity with mammalian Trpc2 orthologs.

Identifying VNS-specific genes from teleosts indicates that the genetic components of the VNS-specific signal transduction pathway are present outside of tetrapods. Observed tissue specific-expression patterns of VNS-specific genes in teleosts provide further support for the existence of a VNS precursor in teleost fish (Fig. 5). ${ }^{(21,45,46,62,63,65)}$ Rodent VNOs show the segregated expression of vomeronasal neurons expressing either V1Rs or V2Rs. The V1R-expressing neurons coupling with $G_{\alpha i 2} G$ proteins are spatially distinct from the V2Rexpressing neurons which couple with $G_{\alpha 0} G$ proteins. ${ }^{(21)}$ This $\mathrm{V} 2 \mathrm{R} / \mathrm{G}_{\alpha 0}$ coupling was also identified in goldfish olfactory

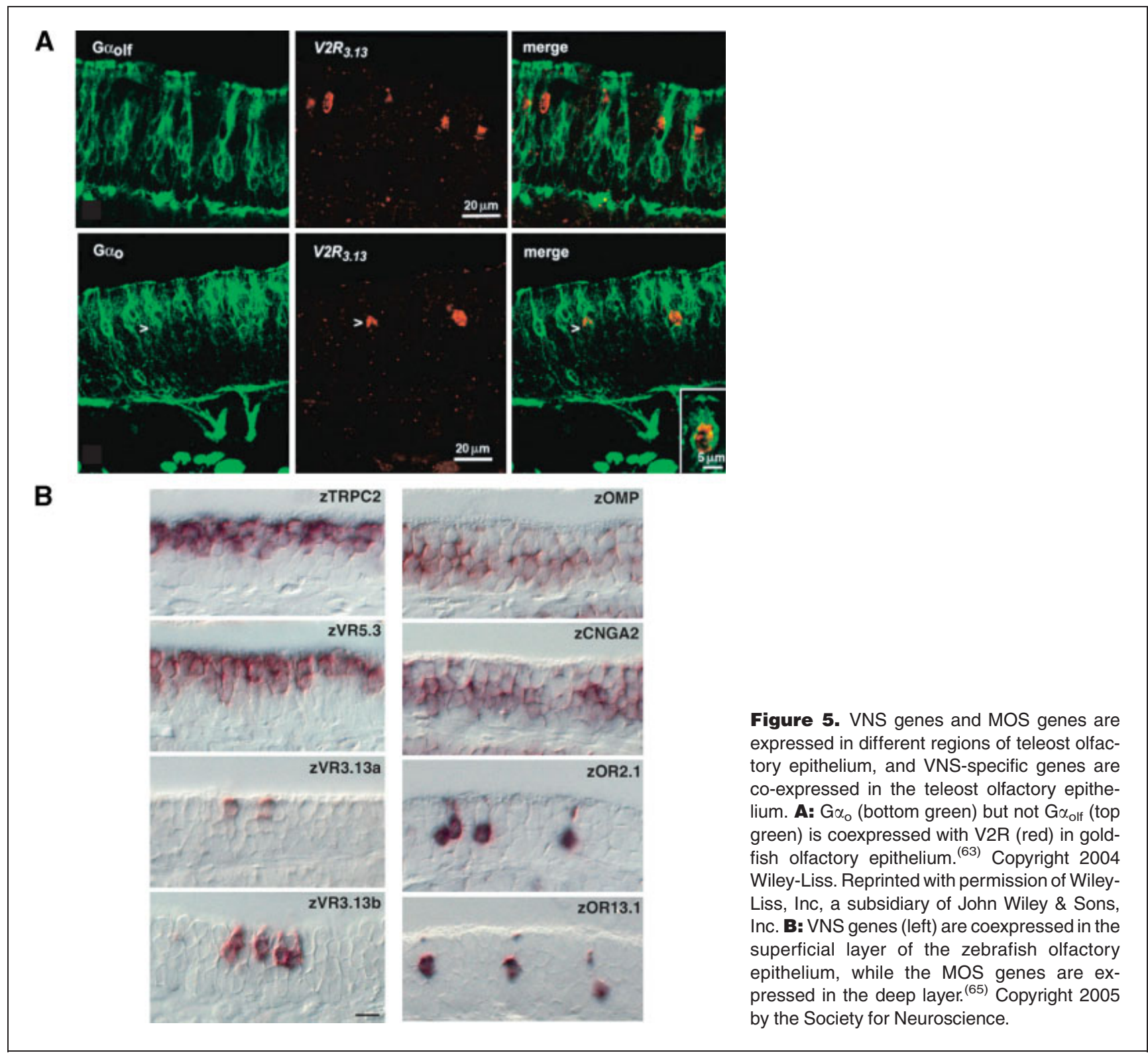

BioEssays $28.7 \quad 715$ 
epithelium, where V2R expression was detected in olfactory neurons immunoreactive to $G_{\alpha 0}$ but not in neurons immunoreactive to $G_{\text {olf }}$ (Fig. 5a). ${ }^{(63)}$ This coupling in a teleost fish indicates that the VNS-specific G-protein/receptor pair existed prior to tetrapods. Furthermore, Trpc2 expression in the teleost olfactory epithelium is limited to the regions that also express teleost V2Rs, and Trpc2 expression was not found in the regions where ORs are expressed (Fig. 5b). ${ }^{(65)}$ These coexpression studies further suggest that the VNS-specific signal transduction pathway existed before the emergence of the morphologically defined VNO in tetrapods (Fig. 6).

Taken together, strong genetic evidence supports a precursor to the VNS in teleost fish. However, this conclusion uncovers a nomenclature problem. The signal transduction pathway exists in taxa where the VNO clearly does not. Thus, the name of the system is problematic as it excludes taxa that have the system-specific signal transduction pathway. Alternative names already present in the literature include accessory olfactory system or peripheral olfactory system. However, to eliminate such hierarchical naming of the vertebrate nasal chemosensory systems, it could simply be called the alternative olfactory system. Such renaming could eliminate the need to add "-like" (e.g. "V1R-like") ${ }^{(62,71)}$ to vomeronasal receptors that are, at the molecular level, vomeronasal receptors. Regardless of the name, our analysis unequivocally reveals that the VNS did not arise as a terrestrial adaptation.

\section{Conclusions}

While most studies of gene evolution focus either on relationships between species or on relationships between genes within a gene family, a third dimension of molecular evolution is using gene evolution to infer the evolution of a physiological system. ${ }^{(57)}$ Here, we used this approach to determine if understanding the evolution of VNS-specific genes would help understand VNS evolution. Strictly from a morphological standpoint, the VNS exists only in tetrapods. Because the hypothesis that the VNS arose as a terrestrial adaptation was rejected, researchers have hypothesized that a precursor system exists in teleost fish. Although teleost fish lack the morphological components of the VNS, teleost homologs of VNS-specific genes have been identified. This and other evidence strongly suggests that the VNS-specific signal transduction pathway existed in the common ancestor of teleosts and tetropods. What is the function of this precursor VNS in teleosts? Some studies indicate that teleost microvillar olfactory receptor cells respond to sex pheromones, ${ }^{(72)}$ indicating that the precursor function is similar to one of the recognized functions of tetrapod VNS. Additionally, since V2Rs have been found to detect proteins, while V1Rs detect smaller volatiles, ${ }^{(73)}$ the precursor system (with many more V2Rs than V1Rs) might be involved in detecting proteins or amino acids and involved in foraging. Regardless, since function can change rapidly, teleost VNS and tetrapod VNS may not have identical functions. In fact, the precursor system

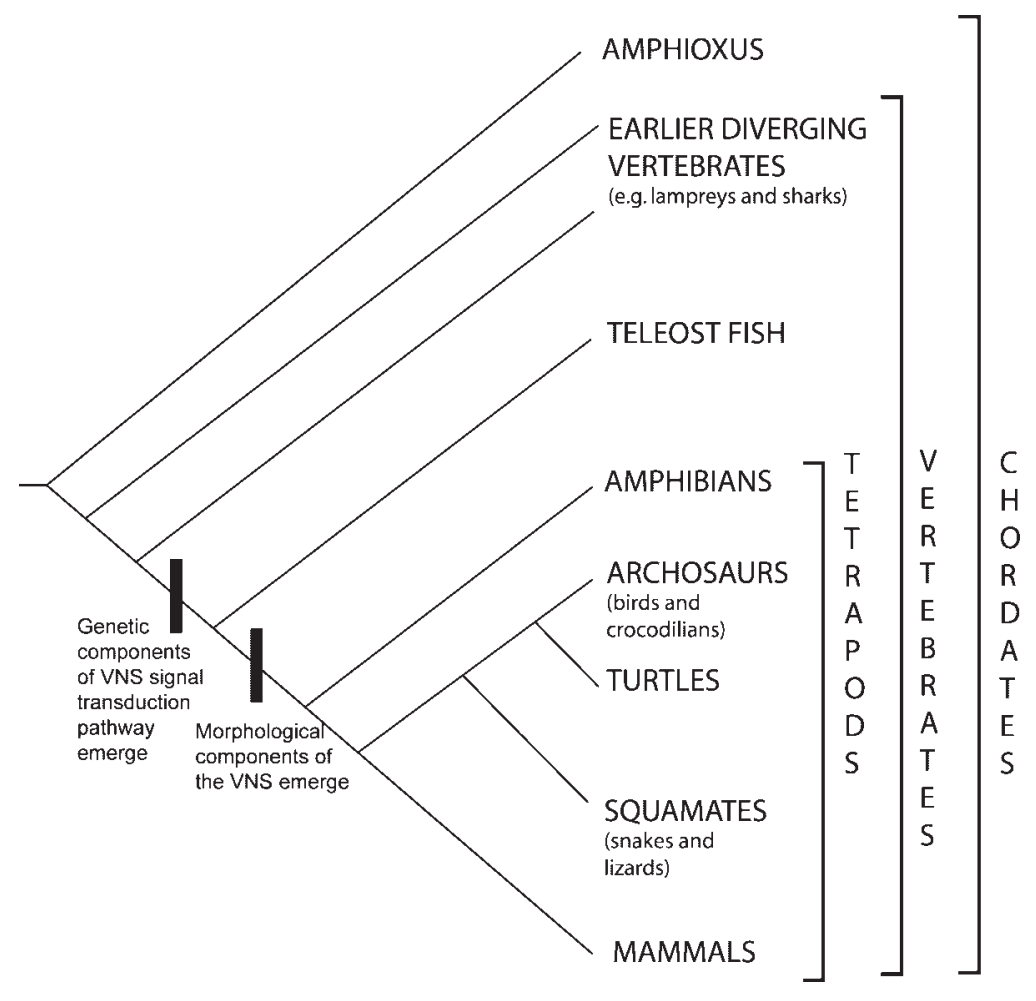

Figure 6. Vertebrate phylogeny reflecting both morphological and genetic aspects of VNS evolution. Note that amphioxus is commonly believed to be the closest invertebrate relative to vertebrates. However, tunicates are recently proposed to be the closest relatives to vertebrates based on molecular phylogenetics. ${ }^{(78)}$

\section{BioEssays 28.7}


might date back even further than the common ancestor of teleosts and tetrapods. To trace the origin of the pathway and VNS, it would be interesting to examine if it exists in even earlier diverging vertebrates, such as sharks, lampreys and even amphioxus (which is the closest invertebrate relative to all vertebrates). Another interesting question is the evolution of VNS in various vertebrate groups. Like the pseudogenization of VNS-specific genes in birds and some primates, the genes might show independent pseudogenizations in other tetrapods that lost the VNS (e.g. some bats). ${ }^{(18,74)}$ Additionally, what will the VNS-specific genes reveal about VNS evolution in squamates (snakes and lizards), which have the mostcomplex VNO type ${ }^{(40)}$ We believe that the evolutionary studies of VNS-specific genes have opened a new dimension of VNS research that would broaden and deepen our understanding of the structure, function and evolution of this both fascinating and enigmatic system. We also believe that the same approach can be used to study other physiological systems, particularly in this era of interdisciplinary, integrative and systems biology.

\section{Acknowledgments}

We thank Peng Shi, Adam Wilkins, and two anonymous reviewers for valuable comments on an earlier version of the manuscript. We thank Ivan Rodriguez for providing us with Fig. 1 and Yoshihiro Yoshiharo and Yuki Sato for providing us with Fig. 5b.

\section{References}

1. Jacobson L, Trotier D, Doving KB. 1998. Anatomical description of a new organ in the nose of domesticated animals by Ludvig Jacobson (1813). Chem Senses 23:743-754.

2. Freitag J, Beck A, Ludwig G, von Buchholtz L, Breer H. 1999. On the origin of the olfactory receptor family: receptor genes of the jawless fish (Lampetra fluviatilis). Gene 226:165-174

3. Cooper WE Jr, Perez-Mellado V. 2002. Pheromonal discriminations of sex, reproductive condition, and species by the lacertid lizard Podarcis hispanica. J Exp Zool 292:523-527.

4. Dawley EM, Crowder J. 1995. Sexual and seasonal differences in the vomeronasal epithelium of the red-backed salamander (Plethodon cinereus). J Comp Neurol 359:382-390.

5. Graves BM, Halpern M, Friesen JL. 1991. Snake aggregation pheromones - source and chemosensory mediation in western ribbon snakes (Thamnophis-Proximus). J Comp Psychol 105:140-144.

6. Del Punta K, Leinders-Zufall T, Rodriguez I, Jukam D, Wysocki CJ, et al. 2002. Deficient pheromone responses in mice lacking a cluster of vomeronasal receptor genes. Nature 419:70-74.

7. Leypold BG, Yu CR, Leinders-Zufall T, Kim MM, Zufall F, et al. 2002 Altered sexual and social behaviors in trp2 mutant mice. Proc Natl Acad Sci USA 99:6376-6381.

8. Stowers L, Holy TE, Meister M, Dulac C, Koentges G. 2002. Loss of sex discrimination and male-male aggression in mice deficient for TRP2. Science 295:1493-1500.

9. Graves BM. 1993. Chemical delivery to the vomeronasal organs and functional domain of squamate chemoreception. Brain Behav Evol 41:198-202.

10. Kardong KV, Berkhoudt H. 1999. Rattlesnake hunting behavior: correlations between plasticity of predatory performance and neuroanatomy. Brain Behav Evol 53:20-28.
11. Placyk JS Jr, Graves BM. 2002. Prey detection by vomeronasal chemoreception in a plethodontid salamander. J Chem Ecol 28:10171036

12. Mandiyan VS, Coats JK, Shah NM. 2005. Deficits in sexual and aggressive behaviors in Cnga2 mutant mice. Nat Neurosci 8:1660-1662.

13. Schaal B, Coureaud G, Langlois D, Ginies C, Semon E, et al. 2003. Chemical and behavioural characterization of the rabbit mammary pheromone. Nature 424:68-72.

14. Xu F, Schaefer M, Kida I, Schafer J, Liu N, et al. 2005. Simultaneous activation of mouse main and accessory olfactory bulbs by odors or pheromones. J Comp Neurol 489:491-500.

15. Eisthen HL. 1992. Phylogeny of the vomeronasal system and of receptor cell types in the olfactory and vomeronasal epithelia of vertebrates. Microsc Res Tech 23:1-21.

16. Bertmar G. 1981. Evolution of vomeronasal organs in vertebrates. Evolution 35:359-366.

17. Jermakowicz WJ 3rd, Dorsey DA, Brown AL, Wojciechowski K, Giscombe CL, et al. 2004. Development of the nasal chemosensory organs in two terrestrial anurans: The directly developing frog, Eleutherodactylus coqui (Anura: Leptodactylidae), and the metamorphosing toad, Bufo americanus (Anura: Bufonidae). J Morphol 261:225-248.

18. Eisthen HL. 2000. Presence of the vomeronasal system in aquatic salamanders. Philos Trans R Soc Lond B Biol Sci 355:1209-1213.

19. Dulka JG. 1993. Sex pheromone systems in goldfish: comparisons to vomeronasal systems in tetrapods. Brain Behav Evol 42:265-280.

20. Eisthen HL. 2004. The goldfish knows: olfactory receptor cell morphology predicts receptor gene expression. J Comp Neurol 477:341-346.

21. Halpern M, Martinez-Marcos A. 2003. Structure and function of the vomeronasal system: an update. Prog Neurobiol 70:245-318.

22. Minke B, Cook B. 2002. TRP channel proteins and signal transduction Physiol Rev 82:429-472.

23. Dulac C, Torello AT. 2003. Molecular detection of pheromone signals in mammals: from genes to behaviour. Nat Rev Neurosci 4: 551-562.

24. Mombaerts P. 2004. Genes and ligands for odorant, vomeronasal and taste receptors. Nat Rev Neurosci 5:263-278.

25. Dulac C, Axel R. 1995. A novel family of genes encoding putative pheromone receptors in mammals. Cell 83:195-206.

26. Ryba NJ, Tirindelli R. 1997. A new multigene family of putative pheromone receptors. Neuron 19:371-379.

27. Herrada G, Dulac C. 1997. A novel family of putative pheromone receptors in mammals with a topographically organized and sexually dimorphic distribution. Cell 90:763-773.

28. Matsunami H, Buck LB. 1997. A multigene family encoding a diverse array of putative pheromone receptors in mammals. Cell 90:775-784.

29. Rodriguez I, Del Punta K, Rothman A, Ishii T, Mombaerts P. 2002. Multiple new and isolated families within the mouse superfamily of $\mathrm{V} 1 \mathrm{r}$ vomeronasal receptors. Nat Neurosci 5:134-140.

30. Tatsura H, Nagao H, Tamada A, Sasaki S, Kohri K, et al. 2001 Developing germ cells in mouse testis express pheromone receptors. FEBS Lett 488:139-144.

31. Boschat C, Pelofi C, Randin O, Roppolo D, Luscher C, et al. 2002. Pheromone detection mediated by a V1r vomeronasal receptor. Nat Neurosci 5:1261-1262

32. Rodriguez I, Mombaerts P. 2002. Novel human vomeronasal receptorlike genes reveal species-specific families. Curr Biol 12:R409-411.

33. Grus WE, Zhang J. 2004. Rapid turnover and species-specificity of vomeronasal pheromone receptor genes in mice and rats. Gene 340: 303-312.

34. Zhang X, Rodriguez I, Mombaerts P, Firestein S. 2004. Odorant and vomeronasal receptor genes in two mouse genome assemblies. Genomics 83:802-811.

35. Young JM, Kambere M, Trask BJ, Lane RP. 2005. Divergent V1R repertoires in five species: Amplification in rodents, decimation in primates, and a surprisingly small repertoire in dogs. Genome Res 15: 231-240.

36. Grus WE, Shi P, Zhang YP, Zhang J. 2005. Dramatic variation of the vomeronasal pheromone receptor gene repertoire among five orders of placental and marsupial mammals. Proc Natl Acad Sci USA 102:57675772 
37. Shi P, Bielawski JP, Yang H, Zhang YP. 2005. Adaptive diversification of vomeronasal receptor 1 genes in rodents. J Mol Evol 60:566-576.

38. Lane RP, Cutforth T, Axel R, Hood L, Trask BJ. 2002. Sequence analysis of mouse vomeronasal receptor gene clusters reveals common promoter motifs and a history of recent expansion. Proc Natl Acad Sci USA 99:291-296.

39. Lane RP, Young J, Newman T, Trask BJ. 2004. Species specificity in rodent pheromone receptor repertoires. Genome Res 14:603-608.

40. Takami S. 2002. Recent progress in the neurobiology of the vomeronasal organ. Microsc Res Tech 58:228-250.

41. Zhang J, Webb DM. 2003. Evolutionary deterioration of the vomeronasal pheromone transduction pathway in catarrhine primates. Proc Natl Acad Sci USA 100:8337-8341.

42. Baxi KN, Dorries KM, Eisthen HL. 2005. Is the vomeronasal system really specialized for detecting pheromones? Trends Neurosci.

43. Giorgi D, Rouquier S. 2002. Identification of V1R-like putative pheromone receptor sequences in non-human primates. Characterization of V1R pseudogenes in marmoset, a primate species that possesses an intact vomeronasal organ. Chem Senses 27:529-537.

44. Mundy NI, Cook S. 2003. Positive selection during the diversification of class I vomeronasal receptor-like ( $\mathrm{V} 1 \mathrm{RL})$ genes, putative pheromone receptor genes, in human and primate evolution. Mol Biol Evol 20:18051810.

45. Cao Y, Oh BC, Stryer L. 1998. Cloning and localization of two multigene receptor families in goldfish olfactory epithelium. Proc Natl Acad Sci USA 95:11987-11992.

46. Naito T, Saito Y, Yamamoto J, Nozaki Y, Tomura K, et al. 1998. Putative pheromone receptors related to the $\mathrm{Ca} 2+$-sensing receptor in Fugu. Proc Natl Acad Sci USA 95:5178-5181.

47. Lioubinski O, Alonso MT, Alvarez Y, Vendrell V, Garrosa M, et al. 2006. FGF signalling controls expression of vomeronasal receptors during embryogenesis. Mech Dev 123:17-23

48. Takigami S, Mori Y, Tanioka Y, Ichikawa M. 2004. Morphological evidence for two types of Mammalian vomeronasal system. Chem Senses 29:301-310.

49. Yang H, Shi P, Zhang YP, Zhang J. 2005. Composition and evolution of the $\mathrm{V} 2 \mathrm{r}$ vomeronasal receptor gene repertoire in mice and rats. Genomics 86:306-315.

50. Zhang J, Dyer KD, Rosenberg HF. 2000. Evolution of the rodent eosinophil-associated RNase gene family by rapid gene sorting and positive selection. Proc Natl Acad Sci USA 97:4701-4706

51. Liman ER, Corey DP, Dulac C. 1999. TRP2: a candidate transduction channel for mammalian pheromone sensory signaling. Proc Natl Acad Sci USA 96:5791-5796.

52. Vannier B, Peyton M, Boulay G, Brown D, Qin N, et al. 1999. Mouse trp2, the homologue of the human trpc2 pseudogene, encodes mTrp2, a store depletion-activated capacitative Ca2+ entry channel. Proc Natl Acad Sci USA 96:2060-2064

53. Stamboulian S, Moutin MJ, Treves S, Pochon N, Grunwald D, et al. 2005. Junctate, an inositol 1,4,5-triphosphate receptor associated protein, is present in rodent sperm and binds TRPC2 and TRPC5 but not TRPC1 channels. Dev Biol 286:326-337.

54. Wissenbach U, Schroth G, Philipp S, Flockerzi V. 1998. Structure and mRNA expression of a bovine trp homologue related to mammalian trp2 transcripts. FEBS Lett 429:61-66.

55. Liman ER, Innan H. 2003. Relaxed selective pressure on an essential component of pheromone transduction in primate evolution. Proc Natl Acad Sci USA 100:3328-3332.

56. Wray GA, Abouheif E. 1998. When is homology not homology? Curr Opin Genet Dev 8:675-680

57. Serb JM, Oakley TH. 2005. Hierarchical phylogenetics as a quantitative analytical framework for evolutionary developmental biology. Bioessays 27:1158-1166
58. Ishii T, Hirota J, Mombaerts P. 2003. Combinatorial coexpression of neural and immune multigene families in mouse vomeronasal sensory neurons. Curr Biol 13:394-400.

59. Loconto J, Papes F, Chang E, Stowers L, Jones EP, et al. 2003. Functional expression of murine V2R pheromone receptors involves selective association with the $\mathrm{M} 10$ and $\mathrm{M} 1$ families of $\mathrm{MHC}$ class $\mathrm{Ib}$ molecules. Cell 112:607-618.

60. Piatigorsky J. 2003. Crystallin genes: specialization by changes in gene regulation may precede gene duplication. J Struct Funct Genomics 3:131-137.

61. Hagino-Yamagishi K, Moriya K, Kubo H, Wakabayashi Y, Isobe N, et al 2004. Expression of vomeronasal receptor genes in Xenopus laevis. J Comp Neurol 472:246-256.

62. Pfister P, Rodriguez I. 2005. Olfactory expression of a single and highly variable $\mathrm{V} 1 \mathrm{r}$ pheromone receptor-like gene in fish species. Proc Nat Acad Sci USA 102:5489-5494.

63. Hansen A, Anderson KT, Finger TE. 2004. Differential distribution of olfactory receptor neurons in goldfish: structural and molecular correlates. J Comp Neurol 477:347-359.

64. Dukes JP, Deaville R, Bruford MW, Youngson AF, Jordan WC. 2004. Odorant receptor gene expression changes during the parr-smolt transformation in Atlantic salmon. Mol Ecol 13:28512857.

65. Sato Y, Miyasaka N, Yoshihara Y. 2005. Mutually exclusive glomerular innervation by two distinct types of olfactory sensory neurons revealed in transgenic zebrafish. J Neurosci 25:4889-4897.

66. Hashiguchi Y, Nishida M. 2005. Evolution of vomeronasal-type odorant receptor genes in the zebrafish genome. Gene 362:1928.

67. Murphy FA, Tucker K, Fadool DA. 2001. Sexual dimorphism and developmental expression of signal-transduction machinery in the vomeronasal organ. J Comp Neurol 432:61-74.

68. Taniguchi M, Wang D, Halpern M. 2000. Chemosensitive conductance and inositol 1,4,5-trisphosphate-induced conductance in snake vomeronasal receptor neurons. Chem Senses 25:67-76.

69. Cinelli AR, Wang D, Chen P, Liu W, Halpern M. 2002. Calcium transients in the garter snake vomeronasal organ. J Neurophysiol 87:1449-1472.

70. Gjerstad J, Valen EC, Trotier D, Doving K. 2003. Photolysis of caged inositol 1,4,5-trisphosphate induces action potentials in frog vomeronasal microvillar receptor neurones. Neuroscience 119:193-200.

71. Rodriguez I, Greer CA, Mok MY, Mombaerts P. 2000. A putative pheromone receptor gene expressed in human olfactory mucosa. Nat Genet 26:18-19.

72. Zippel HP, Sorensen PW, Hansen A. 1997. High correlation between microvillous olfactory receptor cell abundance and sensitivity to pheromones in olfactory nerve-sectioned goldfish. Journal of Comparative Physiology a-Sensory Neural and Behavioral Physiology 180:39-52.

73. Krieger J, Schmitt A, Lobel D, Gudermann T, Schultz G, et al. 1999 Selective activation of $\mathrm{G}$ protein subtypes in the vomeronasal organ upon stimulation with urine-derived compounds. J Biol Chem 274:46554662.

74. Bhatnagar KP, Meisami E. 1998. Vomeronasal organ in bats and primates: extremes of structural variability and its phylogenetic implications. Microsc Res Tech 43:465-475.

75. Rodriguez I. 2003. Nosing into pheromone detectors. Nat Neurosci 6: $438-440$.

76. Saitou N, Nei M. 1987. The neighbor-joining method: a new method for reconstructing phylogenetic trees. Mol Biol Evol 4:406-425.

77. Kumar S, Tamura K, Nei M. 2004. MEGA3: Integrated software for Molecular Evolutionary Genetics Analysis and sequence alignment. Brief Bioinform 5:150-163.

78. Delsuc F, Brinkmann H, Chourrout D, Philippe H. 2006. Tunicates and not cephalochordates are the closest living relatives of vertebrates. Nature 439:965-968.

\section{BioEssays 28.7}

